\title{
Patients' Attitudes toward Presence of Trainee Physicians during Consultation at PHCS Riyadh, Saudi Arabia
}

\author{
Running Title: What Patients Perceive of Trainee Doctors Presence during Consultation
}

\author{
Shahad Alwathnani ${ }^{1, *}$, Mostafa Abbas ${ }^{2}$ \\ ${ }^{1}$ Resident, Family Medicine, Prince Sultan Military Medical City, Riyadh, Saudi Arabia \\ ${ }^{2}$ Research Unit, Family and Community Medicine, Occupational Health and Safety, \\ Prince Sultan Military Medical City, Riyadh, Saudi Arabia
}

Copyright $\mathrm{C} 2018$ by authors, all rights reserved. Authors agree that this article remains permanently open access under the terms of the Creative Commons Attribution License 4.0 International License

\begin{abstract}
Background and Aim: Presence of trainee doctors during consultation may create varying atmospheres during consultation. This study was conducted to assess the attitude of patients towards the presence of trainee doctors during consultation and identify factors related to patient satisfaction during consultation. Methods: We conducted a survey using a 37-item self-administered questionnaire on patients aged 18 to 64 years old who presented for consultation at three Primary Health Centers affiliated to Prince Sultan Military Medical City in Riyadh, Saudi Arabia between May and July 2017. Results: There were 417 respondents, 295 (70.7\%) were males. There were 363 respondents $(87.0 \%)$ who considered the trainee as a member of the medical team, $191(45.8 \%)$ knew that they have the right to refuse examination by the trainee. There were $232(55.6 \%)$ who were affected by the general appearance of the trainee, and $335(80.3 \%)$ were affected by the manners of the trainees. There were $361(86.6 \%)$ participants who preferred to be examined by a trainee in the presence of the treating physician. There were $302(72.4 \%)$ participants who preferred that the trainee be of the same gender as them. There were $38(9.1 \%)$ participants who claimed that they had a negative experience with a trainee. The older aged patients, males and the highly educated were more acceptable to the presence of trainees during consultation and examination. Conclusion: Presence of trainees and medical students during consultation and examination is now well-accepted by patients in Saudi Arabia. However, there still exists a significant amount of patients (particularly the female patients) who are reluctant to be examined by trainees and medical students, therefore requiring the presence and supervision of the attending physician in these instances.
\end{abstract}

Keywords Attitudes, Consultation, Medical Students, Perception, Trainees

\section{Introduction}

A great part of education takes pace in real situations. Medical students and trainee doctors get the chance to experience real life situations when they are allowed to be in contact with patients, from whom they learn more and thus refine and enrich their knowledge.

In most teaching hospitals worldwide, patients are used to seeing medical students and even trainee doctors (residents) during consultation and even during rounds. Training physicians can play an active cooperative role and care to build a favorable relationship with patients and create a kind of bond with them.

Several studies have suggested however, that around 3\% of patients exhibit negative feelings while $51 \%$ have positive feeling towards presence of medical students during consultations, regardless of gender [1]. Most patients $(90 \%)$ would actually allow medical students to be involved in their medical care [2]. Furthermore, one study suggested that around $89 \%$ of patients enjoy the presence of medical students and trainees around them, and about $77 \%$ of patients agreed that presence of medical students improved the quality of care that they received $[3,4]$, however some patients allow the presence of medical students and trainees depending on the clinical condition of the patient $[4,5]$. On the other hand, one study showed that majority of the patients agree to be seen by medical student before a general practitioner, while less than $10 \%$ of patients prefer to see their GP alone [6]. 
One particular reason why patients prefer medical students and trainee doctors to be present during consultation is the benefit that they spend more time with their doctors, subsequently better patient education and information on their condition $[7,8]$, and the doctor's personality [5]. On the contrary, patients usually refuse the presence of medical students and trainee doctors due to privacy reasons, low standard of medical care, concerns regarding medical student examining the patient, level of student involvement and prolonged consultation time [9]. Factors that were considered in order patients will allow medical students and trainee doctors to be present during examination and consultation include telling them in advance about the presence of students, taking permission from them and limiting their involvement in certain times [10].

Many teaching institutions in Saudi Arabia now allow medical students to take their practice in medical hospitals which have more facilities to accommodate students comfortably in their environment. Despite a number of studies done on this subject matter, there are still areas which need to be further elucidated. Thus, we conducted this study to assess the attitude of patients toward presence of training physician during consultations, and to identify determinants for patient satisfaction during consultation.

\section{Methods}

This is a cross-sectional descriptive study that was conducted on randomly selected patients aged 18 to 64 years old who sought consultation at the three Primary Health Centers affiliated to Prince Sultan Military Medical City (namely; Alwazarat Health Center, AlMorooj Health Center, and Senior Officer Health Center) in Riyadh, Saudi Arabia between May and July 2017.

A survey questionnaire was developed specifically for the purpose of the study using questions patterned from previous studies, restructured and fitted to the objectives of this study. The survey questionnaire was piloted on 10 patients to ensure validity of the questionnaire.

The self-administered questionnaire included 4 questions on the demographic profile of the respondents (age, gender, marital status, and educational level), and 29 Likert-type questions ( 3 questions on considerations of the trainee, 2 questions on knowledge of patients' rights, 2 questions on the effect of trainees appearance and manners on the patient, 12 questions on patient's preferences, and 10 questions on patient's feelings and experiences with a trainee). The responses to the Likert scale type questions were rated as $1=$ strongly disagree, $2=$ disagree, $3=$ =neutral , $4=$ agree, and $5=$ strongly agree).

Sample size was determined using the equation, $\frac{Z^{2} *(p) *(1-p)}{c^{2}}$

Where $\mathrm{Z}$ is the confidence level, $\mathrm{p}$ is the percentage picking a choice, and $\mathrm{c}$ is the confidence interval. The calculated sample size was 287 .

Inclusion criteria included adult consenting patients aged 18-64 years old, and exclusion criteria were patients below 18 years old and patients above 64 years old, patients who were unable to write or read, patients who were seriously ill, confused and patients who had difficult to reply or answer the questions.

Data were collected, encoded and analyzed using the Statistical Package for Social Sciences (SPSS) version 21.0 (IBM-SPSS Inc., Armonk, NY, USA). Student T-test was done to compare quantitative or continuous variables and results was expressed as mean \pm standard deviation (SD). Chi-square test was done for qualitative or categorical variables and results were presented as percentage. A p of $<0.05$ was considered statistically significant.

The study was approved by the Ethical Committee for Research Studies of PSMMC (Project No. 959, Date approved 02 May series of 2017).

Confidentiality is strictly ensured that no identifiers and contact numbers of patients were kept confidential. Informed consent was secured from all patients who participated in the study.

\section{Results}

A total of 417 patients participated in the study, 295 $(70.7 \%)$ females and $122(29.3 \%)$ males. There were 191 participants $(45.8 \%)$ who have met the trainee physician before the interview or before they were examined. Table 1 shows the demographic profiles of the participants. 
Table 1. Demographic profile of the 417 participants in the survey on "patients' attitude toward presence of training physicians during consultation"

\begin{tabular}{|c|c|c|}
\hline Demographic variables & $\mathrm{n}$ & $\%$ \\
\hline Gender & 122 & 29.3 \\
Male & 295 & 70.7 \\
Female & 203 & 48.7 \\
\hline Age groups & 132 & 31.7 \\
<30 years old & 82 & 19.7 \\
\hline - 40 years old & & 35.5 \\
>40 years old & 148 & 60.2 \\
\hline Marital status & 251 & 3.8 \\
Single & 16 & 0.5 \\
Married & 2 & 3.1 \\
Divorced & & \\
\hline Widow & 13 & 3.4 \\
Educational level & 130 & 31.2 \\
Sead and write & 239 & 57.3 \\
\hline
\end{tabular}

Table 2 shows the participants' responses to the 29 Likert-type questions. Majority of the participants consider the trainee as a member of the medical team $(n=363,87.0 \%)$ and is licensed to practice $(\mathrm{n}=238,57.1 \%)$. There were 237 participants (56.9\%) who disagreed and strongly disagreed that "it is their right as a patient to refuse answering trainee questions". There were 191 participants $(45.8 \%)$ who agreed / strongly agreed that it is their right to refuse examination by the trainee, whereas 181 (43.4\%) disagreed/ strongly disagreed on this notion. There were 232 participants $(55.7 \%)$ who claimed that the trainee's general appearance affect their cooperation for treatment and examination, whereas $335(80.3 \%)$ claimed that the manners of the trainees affect their cooperation for treatment and examination.

With regards to their preferences for examination and treatment, $249(59.7 \%)$ disagreed / strongly disagreed that they will be examined by the treating physician without a trainee, and $361(86.6 \%)$ preferred to be examined by a trainee in the presence of the treating physician. There were 265 participants (63.5\%) who disagreed / strongly disagreed that the presence of a trainee without participation in examination and treatment will affect their medical care. Majority of the participants will allow the trainee to ask them questions during consultation $(n=384$, $92.1 \%)$, and more than half of the participants $(\mathrm{n}=284$, $68.1 \%$ ) will allow the trainees to conduct physical examinations on them. However, $408(97.8 \%)$ of the participants prefer to have the training physician to be present when trainee asks them questions during consultation, and $369(88.5 \%)$ prefer the presence of the treating physician when trainees perform physical examinations on them. There were 302 (72.4\%) participants who prefer that the trainee will be of the same gender as them. (Table 2)

With regards to patients' feelings and experiences with a trainee, a significant proportion of respondents felt and had positive good experiences with a trainee doctor. The proportion of respondents who did not feel humiliated when asked on questions about alcohol intake and extramarital sex was significantly greater among respondents who experienced these feelings ( $\mathrm{n}=201,48.2 \%$ versus $n=145, p<0.001)$. Similarly, there were more respondents who were not embarrassed when examined in front of trainees $(n=260,64.2 \%$ versus $n=106,25.4 \%$, $\mathrm{p}<0.001)$. There were significantly more respondents who claimed that their cooperation and the information they give to a trainee doctor is the same with their treating physician $(\mathrm{n}=227,54.4 \%$ versus $\mathrm{n}=126,30.2 \%, \mathrm{p}<0.001$; and, $\mathrm{n}=231,55.4 \%$ versus $\mathrm{n}=127,30.4 \%, \quad \mathrm{p}<0.001$ respectively). A significant proportion of respondents claimed that the trainee's questions help them with their complaints compared to those who don't ( $\mathrm{n}=197,43.2 \%$ versus $\mathrm{n}=110,26.4 \%, \mathrm{p}<0.001)$. Moreover, a significant proportion of respondents $(n=187,44.8 \%)$ claimed that their mood does not affect their cooperation with trainees compared to those who do $(\mathrm{n}=158,37.9 \%), \mathrm{p}=0.0432$. There were significantly more respondents who claimed that the presence of trainee doctors during consultation does not interfere with their relationship and does not affect their time with their treating physician $(p<0.001$ and $\mathrm{p}<0.001$, respectively). A significant majority of the respondents $(\mathrm{n}=248,59.5 \%)$ believed that trainees involvement during consultation improves their medical care compared to those who believed that the presence of trainees does not improve their medical care $(\mathrm{p}<0.001)$. (Table 2) 
Table 2. Participants' responses to the 29 Likert-type questions and the mean (SD) for each question

\begin{tabular}{|c|c|c|c|c|c|c|}
\hline Questions & $\begin{array}{c}\text { Strongly } \\
\text { agree } \\
\text { n (\%) }\end{array}$ & $\begin{array}{l}\text { Agree } \\
\text { n (\%) }\end{array}$ & $\begin{array}{l}\text { Neutral } \\
\text { n (\%) }\end{array}$ & $\begin{array}{l}\text { Disagree } \\
\text { n (\%) }\end{array}$ & $\begin{array}{c}\text { Strongly } \\
\text { disagree } \\
\text { n (\%) }\end{array}$ & Mean (SD) \\
\hline \multicolumn{7}{|l|}{ A. Considerations of the trainee } \\
\hline $\begin{array}{l}\text { I consider the trainee as a member of the medical } \\
\text { team }\end{array}$ & $119(28.5)$ & $244(58.5)$ & $37(8.9)$ & $15(3.6)$ & $2(0.5)$ & $4.11(0.74)$ \\
\hline $\begin{array}{l}\text { I consider the trainee as a physician licensed to } \\
\text { practice }\end{array}$ & $54(12.9)$ & $184(44.1)$ & $\begin{array}{c}103 \\
(24.7)\end{array}$ & $70(16.8)$ & $6(1.4)$ & $3.50(0.97)$ \\
\hline $\begin{array}{l}\text { I consider the trainee as a physician who does not } \\
\text { participate in the treatment plan }\end{array}$ & $21(5.0)$ & $116(27.8)$ & $77(18.5)$ & $\begin{array}{c}171 \\
(41.0)\end{array}$ & $32(7.7)$ & $2.82(1.08)$ \\
\hline \multicolumn{7}{|l|}{ B. Knowledge of the patient's rights } \\
\hline $\begin{array}{l}\text { It is my right as a patient to refuse answering } \\
\text { trainee questions }\end{array}$ & $23(5.5)$ & $100(24.0)$ & $57(13.7)$ & $\begin{array}{c}190 \\
(45.6)\end{array}$ & $47(11.3)$ & $2.67(1.12)$ \\
\hline $\begin{array}{l}\text { It is my right as a patient to refuse examination by } \\
\text { a trainee }\end{array}$ & $38(9.1)$ & $153(36.7)$ & $45(10.8)$ & $\begin{array}{c}150 \\
(36.0)\end{array}$ & $31(7.4)$ & $3.04(1.18)$ \\
\hline \multicolumn{7}{|c|}{ C. Effect of trainee's appearance and manners on the patient } \\
\hline $\begin{array}{l}\text { The trainee's general appearance affect my } \\
\text { cooperation }\end{array}$ & $85(20.4)$ & $147(35.3)$ & $51(12.2)$ & $94(22.5)$ & $40(9.6)$ & $3.34(1.29)$ \\
\hline The manners of trainees affect my cooperation & $153(36.7)$ & $182(43.6)$ & $36(8.6)$ & $37(8.9)$ & $9(2.2)$ & $4.04(1.00)$ \\
\hline \multicolumn{7}{|c|}{ D. Patient's preferences on treatment and examination } \\
\hline $\begin{array}{l}\text { I prefer to be examined by the treating physician } \\
\text { without a trainee }\end{array}$ & $40(9.6)$ & $79(18.9)$ & $49(11.8)$ & $\begin{array}{c}222 \\
(53.2)\end{array}$ & $27(6.5)$ & $2.72(1.14)$ \\
\hline $\begin{array}{l}\text { I prefer to be examined by a trainee with the } \\
\text { treating physician }\end{array}$ & $126(30.2)$ & $235(56.4)$ & $15(3.6)$ & $37(8.9)$ & $4(1.0)$ & $4.06(0.88)$ \\
\hline $\begin{array}{l}\text { I prefer to be examined by a trainee without a } \\
\text { treating physician }\end{array}$ & $16(3.8)$ & $55(13.2)$ & $47(11.3)$ & $\begin{array}{c}221 \\
(53.0)\end{array}$ & $78(18.7)$ & $2.30(1.04)$ \\
\hline $\begin{array}{l}\text { The presence of a trainee without participation } \\
\text { will affect my medical care }\end{array}$ & $26(6.2)$ & $56(13.4)$ & $70(16.8)$ & $\begin{array}{c}192 \\
(46.0)\end{array}$ & $73(17.5)$ & $2.45(1.11)$ \\
\hline $\begin{array}{l}\text { I will allow if trainee asks me questions during } \\
\text { consultation }\end{array}$ & $123(29.5)$ & $261(62.6)$ & $19(4.6)$ & $7(1.7)$ & $7(1.7)$ & $4.17(0.73)$ \\
\hline I will allow the trainee to examine me physically & $42(10.1)$ & $242(58.0)$ & $48(11.5)$ & $72(17.3)$ & $13(3.1)$ & $3.55(0.99)$ \\
\hline $\begin{array}{l}\text { I prefer the presence of the treating physician } \\
\text { when trainee asks questions }\end{array}$ & $172(30.5)$ & $236(56.6)$ & $34(8.2)$ & $17(4.1)$ & $3(0.7)$ & $4.12(0.78)$ \\
\hline $\begin{array}{l}\text { I prefer the presence of the treating physician } \\
\text { when trainee examines me }\end{array}$ & $139(33.3)$ & $230(55.2)$ & $22(5.3)$ & $21(5.0)$ & $5(1.2)$ & $4.14(0.82)$ \\
\hline $\begin{array}{l}\text { I prefer the presence of treating physician when } \\
\text { trainee examine and ask me }\end{array}$ & $146(35.0)$ & $229(54.9)$ & $13(3.1)$ & $28(6.7)$ & $1(0.2)$ & $4.18(0.80)$ \\
\hline $\begin{array}{l}\text { I prefer to be informed in advance that trainee will } \\
\text { be present during examination }\end{array}$ & $140(33.6)$ & $176(42.2)$ & $44(10.6)$ & $53(12.7)$ & $4(1.0)$ & $3.95(1.02)$ \\
\hline $\begin{array}{l}\text { I prefer that the trainee will be same with my } \\
\text { gender }\end{array}$ & $154(36.9)$ & $148(35.5)$ & $37(8.9)$ & $59(14.1)$ & $19(4.6)$ & $3.86(1.19)$ \\
\hline $\begin{array}{l}\text { I feel difficulties in discussing my personal } \\
\text { history with a trainee }\end{array}$ & $67(16.1)$ & $118(28.3)$ & $63(15.1)$ & $\begin{array}{c}138 \\
(33.1)\end{array}$ & $31(7.4)$ & $3.12(1.24)$ \\
\hline \multicolumn{7}{|l|}{ E. Patient's feelings and experiences with a trainee } \\
\hline $\begin{array}{l}\text { I feel humiliated if I will ask questions about } \\
\text { alcohol intake and extramarital sex }\end{array}$ & $65(15.6)$ & $80(19.2)$ & $71(17.0)$ & $\begin{array}{c}160 \\
(38.4)\end{array}$ & $41(9.8)$ & $2.92(1.26)$ \\
\hline $\begin{array}{l}\text { I feel embarrassed when doctor examines me in } \\
\text { front of trainees }\end{array}$ & $40(9.6)$ & $66(15.8)$ & $51(12.2)$ & $\begin{array}{c}208 \\
(19.9)\end{array}$ & $52(12.5)$ & $2.60(1.18)$ \\
\hline $\begin{array}{l}\text { My cooperation with a trainee is less than with a } \\
\text { treating physician }\end{array}$ & $36(8.6)$ & $90(21.6)$ & $64(15.3)$ & $\begin{array}{c}177 \\
(42.4)\end{array}$ & $50(12.0)$ & $2.72(1.18)$ \\
\hline $\begin{array}{l}\text { Information accuracy that is given to trainee is } \\
\text { different to a treating physician }\end{array}$ & $38(9.1)$ & $89(21.3)$ & $59(14.1)$ & $\begin{array}{c}169 \\
(40.5)\end{array}$ & $62(14.9)$ & $2.69(1.22)$ \\
\hline $\begin{array}{l}\text { The way a trainee asks questions does not help me } \\
\text { with my complains }\end{array}$ & $27(6.5)$ & $83(19.9)$ & $\begin{array}{c}110 \\
(26.4)\end{array}$ & $\begin{array}{c}174 \\
(41.7)\end{array}$ & $23(5.5)$ & $2.80(1.03)$ \\
\hline $\begin{array}{l}\text { My cooperation with trainees is affected by my } \\
\text { mood }\end{array}$ & $54(12.9)$ & $104(24.9)$ & $72(17.3)$ & $\begin{array}{c}145 \\
(34.8)\end{array}$ & $42(10.1)$ & $2.96(1.23)$ \\
\hline $\begin{array}{l}\text { Trainee's participation in consultation takes too } \\
\text { much time }\end{array}$ & $27(6.5)$ & $85(20.4)$ & $98(23.5)$ & $\begin{array}{c}168 \\
(40.3)\end{array}$ & $39(9.4)$ & $2.74(1.09)$ \\
\hline $\begin{array}{l}\text { Having trainees involved interferes with the } \\
\text { relationship with my doctor }\end{array}$ & $18(4.3)$ & $40(9.6)$ & $69(16.5)$ & $\begin{array}{c}230 \\
(55.2)\end{array}$ & $60(14.4)$ & $2.34(0.98)$ \\
\hline $\begin{array}{l}\text { Trainee's participation decrease my time with my } \\
\text { doctor }\end{array}$ & $26(6.2)$ & 89 (21.3) & 80 (19.2) & $\begin{array}{c}179 \\
(42.9)\end{array}$ & $43(10.3)$ & $2.70(1.10)$ \\
\hline Trainee's involvement improves my medical care & $84(20.1)$ & $164(39.3)$ & $97(23.3)$ & $60(14.4)$ & $12(2.9)$ & $3.59(1.05)$ \\
\hline
\end{tabular}


There were 38 (9.1\%) participants who claimed that they had a negative experience with a trainee before the study was conducted. Of these, 14 participants $(10.5 \%)$ claimed that the negative experience was purely miscommunication, whereas $13(3.1 \%)$ claimed it was because of the low quality of care. Seven participants $(1.7 \%)$ claimed they received maltreatment from trainees, and $4(1.0 \%)$ were not satisfied with the general appearance of the trainees.

The older aged group of participants ( $>30$ years old) significantly considered the trainee as part of the medical team involved in their treatment plan $(\mathrm{p}=0.001)$, and they significantly preferred to be examined by the treating physician with or without the trainee's presence $(\mathrm{p}=0.035)$ compared to the younger aged group of participants. Furthermore, participants who were aged 30 years old and more preferred to have their treating physician during consultations and examinations compared to those $<30$ years old $(p=0.012)$. Feeling of humiliation was significantly greater among younger participants $(<30$ years old $)$ than the older aged patients $(\mathrm{p}=0.049)$, cooperation with a trainee was significantly better among older aged patients $(\mathrm{p}=0.004)$, and disclosure of information to the treating physician compared to the trainee was not significantly different among the older age patients aged 30 and above $(\mathrm{p}=0.026)$.

On the other hand, females significantly considered trainees as a member of the team who participated in the treatment plan $(\mathrm{p}=0.033)$ compared to males, although males significantly appreciated the presence of trainees participation in their medical care compared to females $(p=0.002)$. Females significantly preferred to be examined by the treating physician without the trainee compared to males $(p=0.003)$, and males significantly allowed trainees to examine them physically compared to females $(\mathrm{p}=0.001)$. Females also significantly preferred to be examined by trainees of the same gender than males $(p=0.036)$.

Patients who have a higher level of education (university or more) significantly considered trainees as part of the medical team who participated in the treatment plan $(p=0.007)$. The highly educated patients were significantly more affected by the trainees' manners and appearance $(p=0.011)$. They were also the group of participants who were significantly more keen of the trainees participation in their medical care and were greatly affected by trainees' non-participation $(\mathrm{p}<0.001)$, and prefer to be examined by the treating physician $(\mathrm{p}<0.001)$, although allowing trainees to ask them questions with the presence of the treating physician $(\mathrm{p}=0.034)$. However, their cooperation to the trainees was significantly more compared to other educational level groups $(\mathrm{p}=0.040)$. Married women in particular significantly preferred trainees of the same gender when it comes to examination and consultation $(\mathrm{p}=0.040)$.

The mean $( \pm \mathrm{SD})$ Likert scores were highest with positively-phrased questions on "prefer the presence of treating physician when trainee asks them questions" (4.18 \pm 0.80 ), followed by question on "allow trainees to ask them questions during consultations $(4.17 \pm 0.73)$, and prefer the presence of the treating physician when trainees examines them $(4.14 \pm 0.82)$. Patients were negatively affected by trainees' manners during examination and consultation (4.04 \pm 1.00$)$, discussing personal history (3.12 \pm 1.24$)$, and their mood towards cooperation with trainees $(2.80 \pm 1.03)$. (Table 2$)$

\section{Discussion}

This study showed that a significant majority of our studied Saudi population had a high esteem towards the medical practitioners whether they are trainees or already practicing doctors. This was evident in our results that $87.0 \%$ of our respondents considered the trainee as a member of the medical team. There were $232(55.7 \%)$ respondents who claimed that the trainee's general appearance affected their cooperation for treatment and examination by the medical trainee / student, which was significantly lower compared to $81.0 \%$ reported by Abdulghani et al. in 2008 [10]. This particular disparity in the percentage of perception between the two studies may be explained by the type of patients that were surveyed, ours in a health center setting, whereas Abdulghani's study was done in a tertiary referral hospital. There are several health care centers in Riyadh; however, patients most probably choose to visit the larger tertiary hospitals for consultation since there are also several major government hospitals in Riyadh that offers free medical services to the general population [11]. Furthermore, in contrast to the Abdulghani's study in 2008, our study showed that patients through the years has learned to accept the presence of medical students and trainee doctors during consultation and examination, particularly patients who attend to clinics in the larger tertiary and teaching hospitals.

On the other hand, less than half of the respondents knew their rights; right to refuse consultation with a trainee $(\mathrm{n}=123,29.5 \%)$ and right to refuse examination by a trainee $(\mathrm{n}=191,45.8 \%)$. (Table 2) This study showed that only $43.1 \%$ practically knew of their right to refuse answering questions. In contrast to this, Abdulghani's 2008 study [10] showed that patients' knowledge of their right to refuse student involvement in tertiary hospitals was higher than in general hospitals $96.70 \%$ versus $12 \%$. This present study showed $43.1 \%$ of patients knew their rights to refuse presence of medical students / trainees during consultation and examination.

One particular finding in this study was that $59.7 \%$ disagreed / strongly disagreed that they were allowed to be examined by the treating physician without a trainee, and $86.6 \%$ preferred to be examined by a trainee with the treating physician's presence. Is this an evolution of patients' medical recognition of the importance of medical trainees' presence during examination and consultation? 
Or probably, they were just allowed to interact with their doctors (both trainees and treating physician) for a longer period of time. Patients usually are willing to share information and are willing to undergo physical examination when they know who they are sharing their information with and who will be conducting their examination [12]. Medical students and trainee doctors are usually eager and part of their training is to show empathy to patients. The fact is, medical students and trainee doctors usually respond to patients' queries diligently and are extra careful in conducting physical examination on patients because they know they are still under training and they are being watched and guided by their training consultants and supervisors. In fact, $92.1 \%$ of our study participants allowed the trainee to ask them questions during consultation, and $68.1 \%$ allowed the trainees to conduct physical examinations on them.

This study also showed that there were respondents, who experienced difficulties when discussing personal issues with a trainee, felt humiliated on sensitive questions and even felt embarrassed when being examined in front of trainees by their treating doctors. This is probably due to the constant change of the trainees attending on them. Medical students and trainees usually do not stay for a longer time in one specialty, since part of their training is rotating in various specialties and subspecialties. There were studies that showed displeasure of patients to constant changes of attending doctors on consultation and examination [13]. Whether the results of this study pertaining to the accuracy of information given to trainee in contrast to the information given to their treating physician is brought about by the patient's disclosure and withholding of relevant information, this can also be brought about by the clinical experience and expertise of the treating physicians in extracting the needed information from the patient. Studies have shown that the more experienced physicians are more likely to receive answers to their questions compared to trainees [14]. Patients are not obliged to participate in the training of trainees. It has been explained well by Lowe et al, that patients are "obliged" to cooperate with trainees during consultation and examination for the trainees benefit more than the patient [15]. Furthermore, patients may overestimate or underestimate their understanding of confidentiality, thus patients may trust or distrust trainees or even their treating physicians of pertinent information, and delay the institution of appropriate medical care and treatment [16].

The patients' wide acceptance of medical students and trainees found in this study conforms to the previous study conducted by Abdulghani et al [10] pertaining to their tolerance to the presence of medical students and trainees, however with preference to be attended and examined by their treating physicians, however, in contrast to that study, our study subjects were from the health centers wherein there is a greater probability of trainees / medical students to patients interaction and contact.
Certain characteristics of the patients including older age (probably $>30$ years old, male gender, and highly educated) are fully aware of their rights as patients, and understand the pivotal role of trainees in their medical care. Although, there is a tendency that female patients are reluctant to undergo examination and consultation with trainees, and this could be explained by culture and tradition particularly the interaction between doctors and patients of opposite gender.

\section{Conclusions}

Presence of trainees and medical students during consultation and examination is now well-accepted by patients in Saudi Arabia. However, there still exists a significant amount of patients (particularly the female patients) who are reluctant to be examined by trainees and medical students, and requiring the presence and supervision of the attending physician in these instances. There is a need for strategies to increase acceptance of medical students and trainees as part of the medical team (in PHC sittings.).

\section{REFERENCES}

[1] Cooke F, Galasko G, Ramrakha V, Richards D, Rose A, Watkins J. Medical students in general practice: how do patients feel? British Journal of General Practice. 1996; 46(407):361-2.

[2] York NL, DaRosa DA, Markwell SJ, Niehaus AH, Folse R. Patients' attitudes toward the involvement of medical students in their care. The American journal of surgery. 1995; 169(4):421-3.

[3] Prislin MD, Morrison E, Giglio M, Truong P, Radecki S. Patients' perceptions of medical students in a longitudinal family medicine clerkship. 2001.

[4] O'Flynn N, Spencer J, Jones R. Consent and confidentiality in teaching in general practice: survey of patients' views on presence of students. BMJ. 1997; 315(7116):1142.

[5] Choudhury TR, Moosa AA, Cushing A, Bestwick J. Patients' attitudes towards the presence of medical students during consultations. Medical Teacher. 2006; 28(7):e198-e203.

[6] Haffling A-C, Håkansson A. Patients consulting with students in general practice: Survey of patients' satisfaction and their role in teaching. Medical Teacher. 2008; 30(6):622-9.

[7] Mol SSL, Peelen JH, Kuyvenhoven MM. Patients' views on student participation in general practice consultations: A comprehensive review. Medical Teacher. 2011; 33(7):e397-e400.

[8] Sayed-Hassan RM, Bashour HN, Koudsi AY. Patient attitudes towards medical students at Damascus University teaching hospitals. BMC Medical Education. 2012;12(1):13. 
[9] Ryder N, Ivens D, Sabin C. The attitude of patients towards medical students in a sexual health clinic. Sexually Transmitted Infections. 2005; 81(5):437-9.

[10] Abdulghani H, Al-Rukban M, Ahmad S. Patient Attitudes towards Medical Students in Riyadh, Saudi Arabia. Education for Health. 2008; 21(2):69-.

[11] Health Centers and Health Centers list. Ministry of Health Portal https://www.moh.gov.sa/en/Sectors/Health_centers/Pages/d efault.aspx

[12] Whiddett R, Hunter I, Engelbrecht J, Handy J. Patients' attitude towards sharing their health information. International Journal of Medical Informatics. 2006;75(7):530-41
[13] Nakar S, Levi D, Rosenberg R, Vinker S. Patient attitudes to being treated by junior residents in the community. Patient Education and Counseling. 2010;78(1):111-116

[14] Bergus GR, Randall CS, Sinift SD, Rosenthal DM, Does the structure of clinical questions affect the outcome of curbside consultations with specialty colleagues? Archives of Family Medicine. 2000;9(6):541-47

[15] Lowe M, Kerridge I, McPhee J, Hart C. Do patients have an obligation to participate in student teaching? Medical Education. 2008;42(3):237-41

[16] Sankar P, Mora S, Merz JF, Jones NL. Patient perspectives of medical confidentiality. Journal of General Internal Medicine. 2003;18(8):659-69 